\title{
EFFECTS OF IONS ON THE SLOPE-FACTOR IN ELECTRIC EXCITATION OF NERVE
}

\author{
MASAO SUZUKI ${ }^{1}$ \\ Department of Physiology, College of Medicine, Tiba University, Tiba
}

In the analysis of the process of electric excitation of excitable tissues, the consideration of the following three factors is essential, namely the intensityfactor, the time-factor and the slope-factor. By these factors we mean the quantities which on one side characterize the electric stimulus employed and on the other hand represent properties of the excited tissue determining the effectiveness of the stimulus. Among the three factors stated above, the slope-factor was the first to be recognized (du Bois-Reymond (1), 1848), and until the end of the last century it had been regarded as the sole factor which determined the effectiveness of an electric stimulus (Hermann (2), 1879), although there were some investigations carried out with intention to approach the problem from an entirely different angle ( $c f$. Cremer (3) and Lapicque (4)). Since the advent of this century, the importance of the time-factor has begun to be accepted, due to the introduction of modern techniques (Hoorweg (5), 1892, G. Weiss (6), 1901), and the interest of the nerve-physiologists has since been concentrated on the relationship between the time- and the intensity-factors. But investigations of the slope-factor has also been done from time to time, and recently its importance was emphasized once again (Hill (7), 1936). It might therefore be stated that the mechanism of excitation can only be elucidated in terms of the three factors stated above (Suzuki $(8,9)$, Katz (10)).

In this institute we have long (since 1932) been investigating the problems along this line, choosing the slope-factor as the main subject of research (Suzuki (11)), and a large amount of new data has been obtained and published in Japanese. In this paper I shall describe the newest and most significant experimental results, obtained in collaboration with $T$. Kure, namely the effects of various ions on the slope- and the intensity-factors of nerve.

\section{METHODS}

There are several quantities which serve to characterize the slope-factor: Lucas' (12) minimal gradient, Fabre's (13) "constante linéaire," Hill's (7) constant $\lambda$, Schriever's (14) "Einshleichzeit" and Lapicque's (15) threshold of "climalyse," all these can be regarded as measures of the slope-factor. According to Hill's theory of nerve excitation, the "constante linéaire" (c.l.) is identical with Hill's $\lambda$, although the c.l. has been introduced from an entirely different point of view. It is superior to $\lambda$ in the point that it can be determined by measuring only two values, namely the rheobase and the "pente limite". (see below).

\footnotetext{
1 鈴木正夫

Received for publication March 24, 1950.
} 
In the present investigation Fabre's original method of measuring the c.l. was improved by using a pentode. A satisfactorily constant saturation current can be obtained only by the use of this type of vacuum tube (Suzuki (16)). The diagram of the electrical circuits employed is given in Fig. 1, in which $(A),(B)$

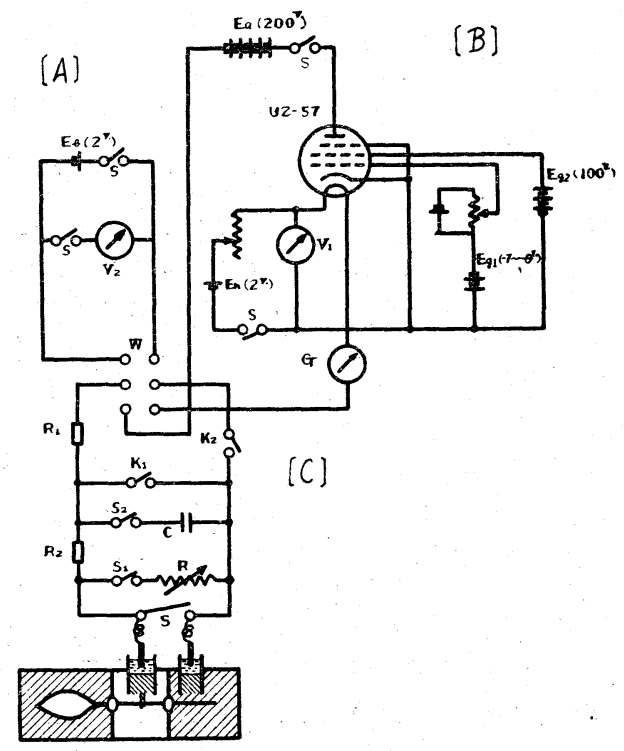

Fig. 1. Schema of the electrical circuits and the electrode box.

and $(C)$ represent respectively the source of a direct current, that of a saturation current and the stimulating circuit. With the circuit $(A)$ connected to $(C)$, in which the contact $S_{1}$ is kept closed and $S_{2}$ open, the threshold for the direct current, namely the rheobasic voltage $V$, can be measured. Connecting $(B)$ with $(C)$, with $S_{2}$ closed and $S_{1}$ open, the "pente limite" (p.1.), nemely the ratio $(I / C)$ of the threshold strength $I$ for the saturation current to the capacity of the condenser $C$, can be determined. The ratio $V /$ p.l., namely $V C / I$, gives the c.1. The capacity $C$ was fixed at a constant value $(10 \mu \mathrm{F}$.) throughout the experiment.

-Stimulating currents were sent into the nerve by the use of a fluid electrode box with the cathode kept in the air (Suzuki (17)). The chamber in which the cathode was kept was filled with various solution to be investigated, and $V$ and the p.l. were determined from time to time after withdrawal of the fluid in the chamber by means of a siphon for a short time. The ions studied were $\mathrm{K}^{\circ}, \mathrm{NH}_{4}{ }^{\circ}$, $\mathrm{Na}{ }^{*}, \mathrm{Ca} \cdot$ and $\mathrm{Mg} \cdot$. The concentration of the solution of these ions was changed by mixing the isotonic solution of their chloride with Ringer solution at various proportions. The notation " $\mathrm{N} / 100$ concentration" used in this paper signifies a mixture of $\mathrm{N}$ parts of the isotonic ion solution with $(100-\mathrm{N})$ parts of the Ringer solution.

\section{A. Alkali metal ions.}

RESULTS

Among the ions of this group $\mathrm{K}^{\cdot}$ and $\mathrm{NH}_{4}{ }^{\circ}$ affect the nerve in the same 
manner. Fig. 2 gives an example of the experiments showing the effect of $\mathrm{K}^{*}$ at high concentrations. Here it is shown that $\mathrm{K}^{\cdot}$ auguments both the rheobase $V$ and the threshold strengh $I$ for the saturation current, the change in the latter

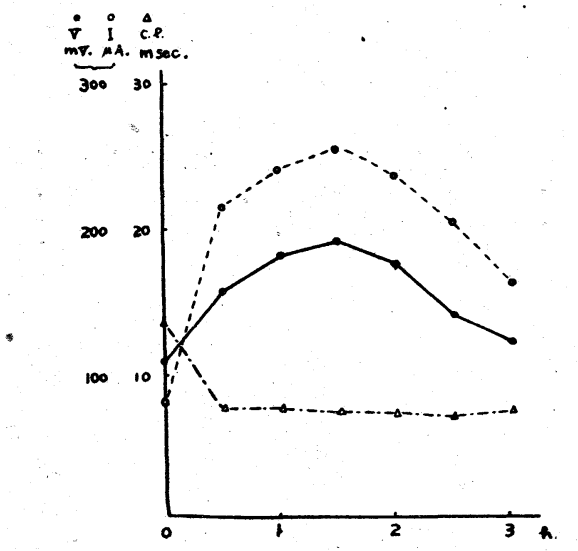

Fig. 2. Effect of $\mathrm{KCl}$-solution of concentration $3 / 100$. Change in $V$, $I$ and the c.l. after the application of the solution. Abscissa represents time in hour, and ordinate $V, I$ and the c.l. in $\mathrm{mV} ., \mu \mathrm{A}$. and msec. respectively.

value being much more pronounced than that in the former and, as the consequence, resulting in a decrease in the c.l., namely $V / I$. Although $V$ and $I$, at this concentration of $\mathrm{K}^{*}$, show a decrease later, the c.l. remains small for a long period. At a low concentration (Fig. 3), the, increase in $V$ and $I$ by the action

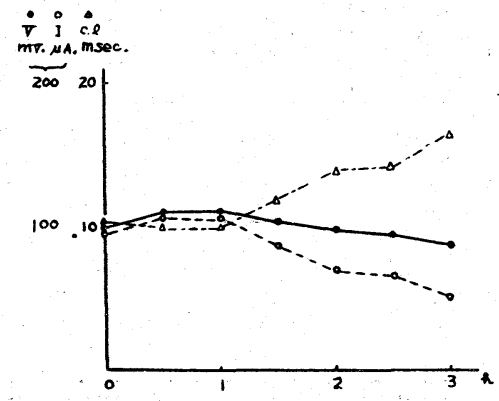

Fig. 3. Effect of $\mathrm{KCl}$-solution of concentration $0.5 / 100$.

of $\mathrm{K}^{\cdot}$ lasts for only a short period and is followed by a decrease in these quantities. As the decrease in $I$ is more pronounced than that in $V$, the value of the c.l., which has at the onset shown a slight decrease, begins now to increase step by step.

The diagram of Fig. 4 is constructed, by collecting the data from 8 different preparations, to show how the c.l. is affected by $\mathrm{K}^{*}$-ion of varying concentrations. It can be seen in this figure that this ion reduces the c.l. at high concentrations and auguments it at low concentrations, and also that there exists a certain intermediate concentration at which its effect on the nerve is not very conspicuous, The effects of $\mathrm{K}^{\cdot}$ on the c.l. at high and low concentrations may at first sight appear opposite to one another. On closer analysis, however, one easily finds that there are at every concentration two different phases in the action of the 


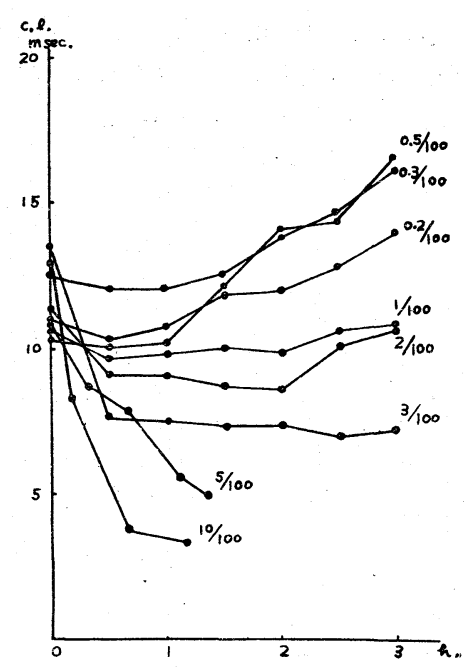

Fig. 4. Effect of $\mathrm{KCl}$-solution of varying concentrations. Ordinate represents the c.l. only.

ion, namely a c.1.-decreasing effect in the early stage and a c.1.-increasing effect in the later stage. At lower concentrations, the c.l.-increasing effect comes into play in an exaggerated manner, while at higher concentrations this c.l.-increasing phase is practically completely "masked" by the opposite, c.l.-dereasing effect.

As regards the changes in $V$ and $I$, it was found that both of them ran parallel with the c.l.: namely an increase in the c.l. is accompanied by a decrease in $V$ and $I$, and vice versa, the change in $I$ being more pronounced than in $V$. Here can also be found the two opposite phases in the course of changes (Fig. 3).

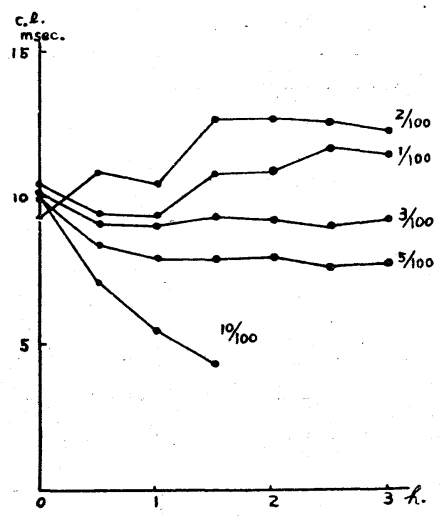

Fig. 5. Effect of $\mathrm{NH}_{4}$-solution of varying concentrations.

Fig. 5 shows that the $\mathrm{NH}_{4}{ }^{-}$-ion brings about a similar, but somewhat weaker, effect upon the c.l. The $\mathrm{Na}^{\circ}$-ion diminishes both $V$ and $I$ and increases the c.l., even when used as a pure isotonic solution of $\mathrm{NaCl}$, what corresponds to the - effect of $\mathrm{K}^{\cdot}$ and $\mathrm{NH}_{4}{ }^{*}$ at low concentrations.

B. Alkaline earth metal ions.

Although the antagonistic actions among the alkali metal and alkaline earth 
metal ions are very familiar to medical students, the present investigation yielded results apparently contradictory to the concept of antagonism. Alkaline earth metal ions were found to affect the c.l. of the nerve in the same manner as alkali metal ions! We shall describe in the first place the effect of $\mathrm{Ca} *$.

As can be seen in Figs. 6 and 7, $\mathrm{Ca} \cdot$ auguments at a high concentration both $V$ and $I$ and diminishes the c.l., and at a low concentration it affects these quantities in the opposite direction, although the effects on $V$ is in the latter case

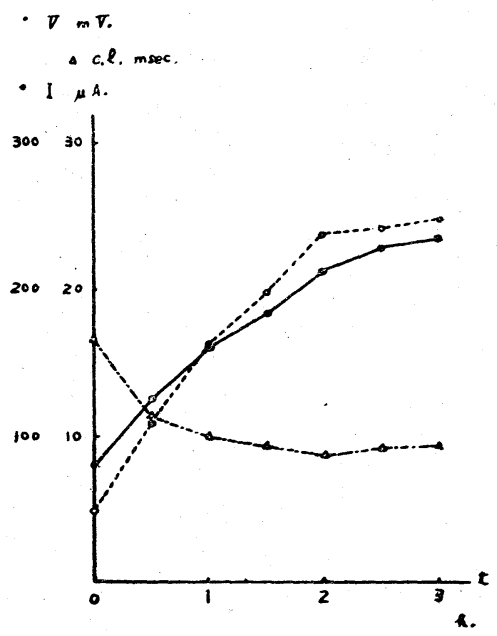

Fig. 6. Effect of $\mathrm{CaCl}_{2}$-solution of concentration $50 / 100$.

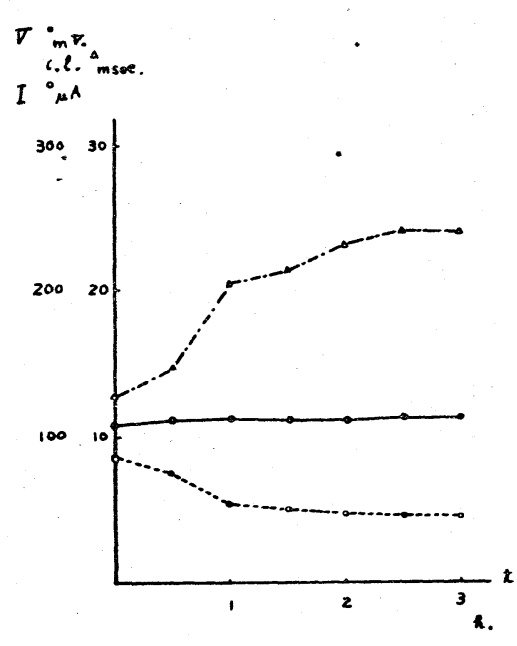

Fig. 7. Effect of $\mathrm{CaCl}_{2}$-solution of concentration $1 / 100$.

very indistinct (Fig. 7). In Fig. 8 one finds that the curves showing the effect of $\mathrm{Ca} \cdot$-ion of varying concentrations closely resemble those furnished in Fig. 4 representing the effect of $\mathrm{K}^{-}$-ion. The data presented in Fig. 9 and comparison of these data with those in Fig. 8 tell us that the relation of $\mathrm{Mg}^{*}{ }^{*}$ - to $\mathrm{Ca}{ }^{*}$-ion is also similar to that between $\mathrm{NH}_{4}^{-}$- and $\mathrm{K}^{\circ}$-ion.

Although the action of all these metal ions are shown to be qualitatively the same, it should be pointed out that there is a remarkable quantitative difference between alkali metal and alkaline earth metal ions. Comparing the data furnished in Figs. 4 and 5 with those in Figs. 8 and 9, one easily finds that the above-stated intermediate concentration, at which there is practically no change in the c.l., is much lower for $\mathrm{K}^{\cdot}$ and $\mathrm{NH}_{4}{ }^{\circ}$ than for $\mathrm{Ca}{ }^{*}$ and $\mathrm{Mg}{ }^{*}$, and also that $\mathrm{K}^{*}$ and $\mathrm{NH}_{4}{ }^{\cdot}$ manifest the c.l.-decreasing effect (at higher concentrations) more pronouncedly than the opposite effect (at lower concentrations), while in $\mathrm{Ca}$ * and $\mathrm{Mg} *$ the c.l.-increasing effect (at lower concentrations) is stronger than the c.l.-decreasing effect (at higher concentrations). One may therefore speak of a quantitative antagonism between the two groups of ions. In fact there is an antagonism between $\mathrm{K}^{*}$ and $\mathrm{Ca}^{*}$ in the range of concentration from 1 to $5 / 100$ and between $\mathrm{NH}_{4}{ }^{*}$ and $\mathrm{Mg} \cdot{ }^{*}$ in the range from 3 to $10 / 100$ (Fig. 10). 


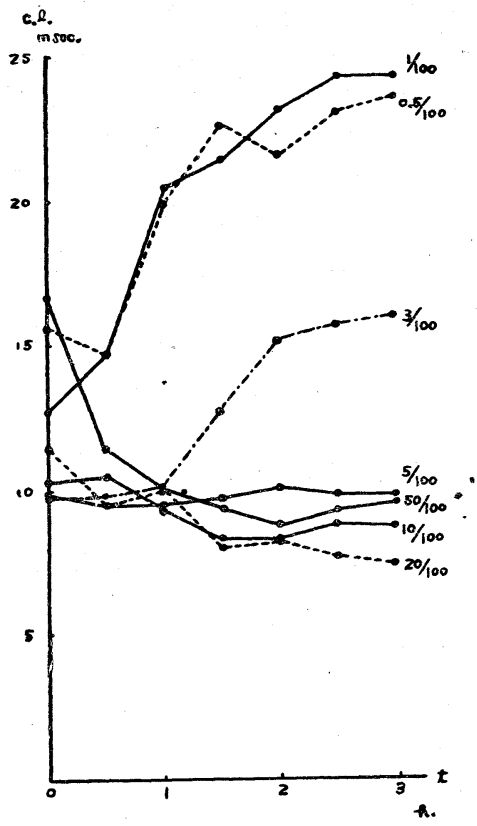

Fig. 8. Effect of $\mathrm{CaCl}_{2}$-solution of varying concentrations.

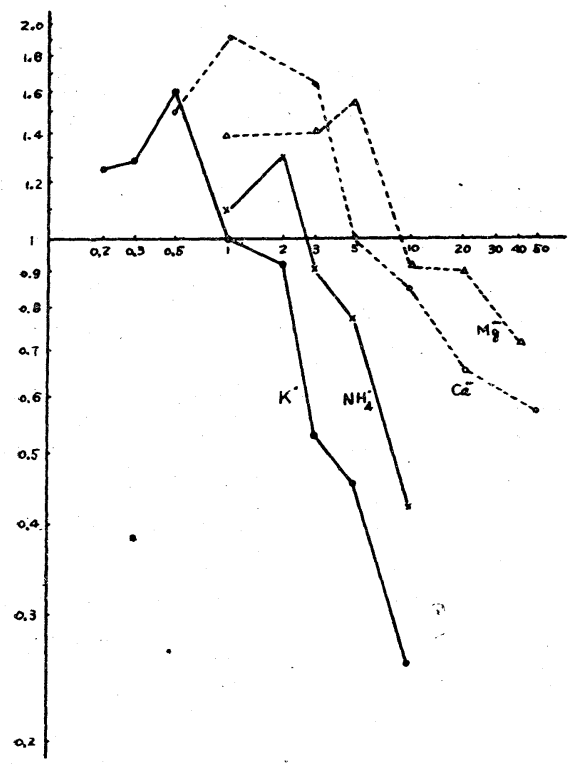

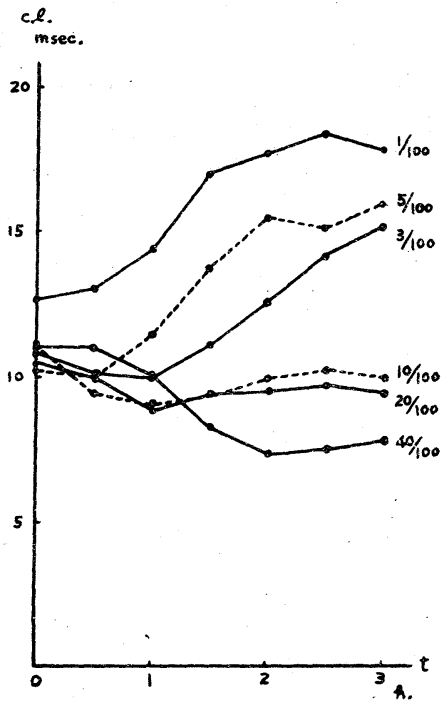

Fig. 9. Effect of $\mathrm{MgCl}_{2}$-solution of varying concentrations.

Fig. 10. Comparison of the effects of four different ions at different concentrations. Ordinate represents the change in the c.l. (the ratio of the final value to the normal), and abscissa the concentrations (expressed in $\mathrm{N}$-values defined in the text) both in logarithmic scale.

\section{DISCUSSION}

The effect of ions upon the slope-factor of the nerve has already been 
subjected to repeated study by Lucas (12), Kahn (18), Jahn (19), Solandt (20) and Schriever and Cebulla (21). All of them describe diminution of $\lambda^{2}$ by Ca ${ }^{*}$-excess and prolongation of $\lambda$ by $\mathrm{Ca} \cdot{ }^{*}$-deficit. Jahn, Solandt and Schriever and Cebulla reported the $\lambda$-decreasing effect of $\mathrm{K}^{*}$-ion. But none of these investigators has carried out a thorough investigation for a wide range of concentration. Ishii (22) found in this institute, in an investigation on the muscle, that the alkali metal ions brought about a $\lambda$-increasing effect at lower concentrations and a $\lambda$ decreasing effect at higher concentrations. But he had no observation on alkaline earth metal ions at low concentrations.

Now we have investigated on the two groups of ions, alkali metal and alkaline earth metal, in a wide range of concentration, and could establish that these two groups of ions affect the c.l. of the nerve in substantially the same manner. Namely, they decrease the c.l. at high concentrations and augument it at low concentrations, and there exists a certain intermediate concentration, at which the effect is not conspicuous. The two opposite effects at high and low concentrations are however considered to be exaggerated manifestations of the two different phases in the effect of ions, namely the c.l.-decreasing effect in the early phase and the c.l.-increasing effect in the later phase. And between the actions of the alkali metal and alkaline earth metal lons, there is a remarkable quantitative difference, and one may speak of a quantitative antagonism between them.

Change in the rheobase due to the action of the ions is also worth discussion. The rheobase $V$ and the minimum effective strength $I$ of the saturation current change their magnitudes in the same direction, and the change in the latter value is more pronounced than that in the former. From this fact it follows that the c.l. changes its magnitude always in the opposite direction to $V$, as the ratio $V / I$ represents the c.l., $I$ being a quantity proportional to the p.l. (cf. "Methods"). The diphasic course of changes, which we saw in the case of the c.l., is also remarkable in the case of $V$ and ' $I$.

This relationship between the changes in the c.l. and $V$ is brought about not only by the action of the ions, but also by the variation of almost all kinds of environmental conditions of excitable tissues, such as temperature, osmotic pressure etc. Suzuki and Ishii (23), reexamining the data obtained by many investigations in the world and our own, called it as "a typical change of excitability" resulting from the variation of the environmental conditions. It signifies that the rheobase (the intensity-factor) and the p.l. (the direct expression of the slope-factor) change their magnitudes in the same direction, the change in the latter value being more pronounced than that in the former.

\section{RUSUMÉ}

1) Effects of alkali metal and alkaline earth metal ions upon the slopefactor and the intensity-factor in electric excitation of nerve were investigated. Fabre's "constante linéaire" (c.l.) was measured by an improved method. The

2 Although the different authors used different quantities to express the slope-factor, I compared their results after expressing the changes in terms of Hill's $\lambda$. 
ions studied were $\mathrm{K}^{*}, \mathrm{NH}_{4}{ }^{\circ}, \mathrm{Na}{ }^{\circ}, \mathrm{Ca}{ }^{*}$ and $\mathrm{Mg}^{*}$. The isotonic solutions of their chloride were mixed with Ringer solution at various proportions, and changes in the c.l. and the rheobase $V$ after the application were traced.

2) All the ions of the two groups, alkali metal and alkaline earth metal ions, affect the c.l. of the nerve in substantially the same manner. At low concentrations they increase the c.l. and at high they decrease it, and there exists a certain intermediate concentration, at which there is practically no change in the c.l. These two opposite effects are however, at every concentration, manifestations of the two different phases in the effect of the ions, namely the c.l.decreasing effect in the early phase and the c.l-increasing effect in the later phase.

3) Between the alkali metal and alkaline earth metal ions there is a remarkable quantitative difference in the value of the intermediate concentration and in the relative intensities of the two different phases stated above. One may therefore speak of a quantitative antagonism between them.

4) The changes in the rheobase $V$ and the threshold strength $I$ for the saturation current run parallel with that in the c.l.; they change their magnitudes in the same direction, the change in $I$ being always more pronounced than that in $V$. This change in $I$ (proportional to the "pente limite," i.e. the direct expression of the slope-factor) and in $V$ (the intensity-factor) is a typical one brought about by the variation of environmental conditions of excitable tissues.

\section{REFERENCES}

1. E. DU BOIS-REYMOND. Untersuchungen über thierische Elektricität 2: 258, 1848, Berlin. Von dem allgemeinen Gesetze der Nervenreizung durch den elektrischen Strom.

2. L. HERMANN. Handbuch der Physiologie 2: 27, 1879, Berlin. Die Erregung des Nerven.

3. M. CREMER. Nagels Handbuch der Physiologie 4: 828, 1909. Die elektrische Nervenerregung.

4. L. LAPICQUE. L'excitabilité en fonction du temps. 1926, Paris.

5. L. HooRWEg. Über die elektrische Nervenreizung. Pflüg. Arch. ges. Physiol. 52: 87, 1892.

6. G. WEISS. Recherches sur l'excitation des nerfs par les"courants de très courtes durées. Compt. rend. Soc. Biol. 53: 253, 1901; Excitation des nerfs par deux ondes successives et très courtes. ibid. 400 ; La loi de l'excitation électrique. ibid. 466.

7. A. V. HILL. Excitation and accommodation in nerve. Proc. roy. Soc. B. 119: 309, 1936.

8. M. SUZUKI. Three factors in electric excitation (in Japanese). Chiba Igk. Z. (Mitt. med. Ges. Chiba) 15: second part 361, 1937.

9. M. SUZUKI. On the slope-factor in electric excitation (in Japanese). Nisshin Igaku (Newest Medical Seience) $27: 1565,1938$.

10. B. KATZ. Electric excitation of nerve. 1939, London.

11. M. SUZUKI. Untersuchungen über den Steilheitsbedarf bei elektrischer Reizung. Jap. $J$. med. Sci., Biophysics 9: 51 *, 1943.

12. K. LUCAS. On the rate of variation of the exciting current as a factor of electric excitation. J. Physiol. $36: 258,1907$.

13. PH. FABRE. L'excitation neuromusculaire par les courants progressifs chez l'homme. Compt. rend. Acad. Sci. 184: 699, 1927; De l'excitation neuromusculaire par ondes cuneiformes. ibid. 1946.

14. H. SCHRIEVER. Über Einschleichen von. Strom. II. Mitt. Z. Biol. $93: 123,1933$. 
15. L. LAPICQUE. Courants progressifs et chronaxie: consideration générale. Compt. rend. Soc. Biol. 125 : 256, 1937 ; Recherches expérimentales sur le seuil d'inefficacité des courants progresifs et ses rapports avec la chronaxie. ibid. 260.

16. M. SUzUKI. Nervenreizung mit dem Sättigungsstrom der Vakuumröhre. Jap.J. med. Sci., Biophysics $6: 257,1939$.

17. M. Suzuki. Zur Frage des Einschleichens des Stromes. Pflüg. Arch. ges. Physiol. 239 : 81, 1937.

18. E. KAHN. Untersuchungen über den Einfluss des $\mathrm{Ca}$ auf die Wirkung der Muskelreizung mit konstantem Strom. Pflüg. Arch. ges. Physiol. 143 : 428, 1912.

19. D. JAHN. Über den Einfluss von Ionen auf die Erregbarkeit des Nerven durch Momentanund Zeit-reize. Pfï̈g. Arch. ges. Physiol. 206 : 66, 1924.

20. D. Y. SOLANDT. The measurement of "accommodation" in nerve. Proc. roy. Soc. B. 119 : $355,1936$.

21. H. SCHRIEver AND R. CEBUlla. Über Erregbarkeitsänderung des Nerven beim Übergang von nicht-rhythmischer zu rhythmischer Reizbeantwortung. Pflüg. Arch. ges. Physiol. $241:$ 1, 1938.

22. T. ISHII. Effects of ions on the slope-factor in electric excitation of frog sartorius (in Japanese). Nihon Seiri. Z. (J. physiol. Soc. Jap.), 7: 1, 1942; Einfluss der Ionen auf den Steilheitsbedarf bei elektrischer Reizung des Froschsartorius. Jap. J. med. Sci, Biophysics $9: 87 *, 1943$.

23. M. SUZUKI AND T. ISHII. On the changes in the intensity- and the slope-factors in electric excitation of frog muscle (in Japanese). Nihon Seiri. Z. 9: 537, 1944. 